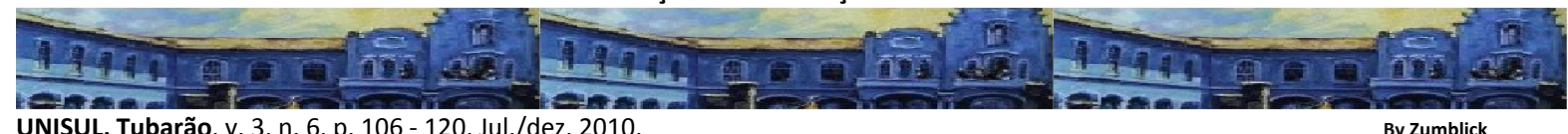

\title{
DE TEMPOS EM TEMPOS OS TEMPOS REVELAM-SE: O IDOSO NOS PROJETOS PEDAGÓGICOS
}

\author{
Juan José Mouriño Mosquera ${ }^{1}$ \\ Maria Otília Borba de Azevedo ${ }^{2}$
}

\section{RESUMO}

A vida não se encerra na velhice. Há espaço para outros sonhos e possibilidades para quem ousa desafiar o tempo. Esse roteiro do nascer ao morrer traz a tônica da complexidade humana. Se as escolas não aliarem o conhecimento aos valores necessários para uma sociedade mais humana ficam fadadas ao monólogo. Não será o desprezo pelas emoções o causador de tanto mal-estar na sociedade atual? A humanidade tanto tem privilegiado a razão em detrimento das emoções, porém, aumentou a fome, novas epidemias têm surgido, guerras, a violência nas escolas avança e o descaso das autoridades mata. Á medida que se indaga, vai-se desvendando esta ciência e fenômeno que é a vida e, descobrindo-se a importância da educação para apontar novos rumos à sociedade vigente, tão carente de compromisso moral e ético.

Palavras-chave: Educação; Idoso/Envelhecimento; projetos pedagógicos.

\section{DE TIEMPO EN TIEMPO LOS TIEMPOS SE DESVELAN: EL ANCIANO EN LOS PROYECTOS PEDAGÓGICOS}

\section{RESUMEN}

La vida no se acaba en la vejez. Hay espacio para otros sueños y posibilidades de quiénes se atreven a desafiar el tiempo. Este guión de la vida del nacer al morirse es la tónica de la complejidad humana. Si las escuelas no unir el conocimiento a los valores necesarios para un más humano de la sociedad, son predestinadas al monólogo. ¿No será el desdén para las emociones el generador del malestar en la sociedad actual? La humanidad de tal manera ha privilegiado la razón en el detrimento de las emociones, sin embargo, ella aumentó el hambre, nuevas epidemias han aparecido, guerras avanzan, la violencia aumentó en las escuelas y la indiferencia de las autoridades mata. Así a la medida que si investiga, se va desnudando esta ciencia y fenómeno que es la vida y, a descubrir la importancia de la educación para señalar las rutas nuevas a la sociedad tan necesitada de compromiso moral y ético.

Palabras-clave: Educación; Anciano/Envejecimiento; proyectos pedagógicos.

\footnotetext{
${ }^{1}$ Doutor em Educação pela Pontifícia Universidade Católica do Rio Grande do Sul (PUCRS), pós-doutorado em Psicologia pela Universidade Autônoma de Madrid, Professor titular da PUCRS, professor visitante da Universidade do Algarve. Endereço eletrônico: mosquera@pucrs.br.

${ }^{2}$ Especialista em cooperativismo pela Universidade do Vale dos Sinos (UNISINOS) e pela Universidade de Deusto em Bilbao/ Espanha, Especialista em Língua Espanhola pela PUCRS, Mestre em Educação pela PUCRS, Professora visitante da UNISINOS. Exerce suas atividades na área como consultora independente. Endereço eletrônico: otilia.m@hotmail.com.
} 


\section{INTRODUÇÃO ${ }^{3}$}

A educação pode descortinar um futuro de valorização para o idoso. 0 meio educacional deve preparar as crianças e jovens para essa fase e para um acolhimento digno para com o adulto tardio, possibilitando às disciplinas dialogarem entre si, harmonizando conteúdos para uma educação integral. A troca intergeracional é eficaz para o meio escolar e social entre diferentes gerações, portanto, há necessidade da educação trabalhar conteúdos pertinentes, atendendo também aos preceitos legais do Estatuto do Idoso.

Trazer à escola o fenômeno do desenvolvimento do adulto com ênfase ao idoso, permeando alguns temas psicológicos, biológicos e aspectos sociais relevantes que acompanham este processo, permite compreender as mudanças que ocorrem no ser humano com a idade, ademais de contribuir para uma maior manifestação de respeito e afeto pelo idoso. Tal temática, muitas vezes esquecida no cotidiano escolar, pede a uma educação do terceiro milênio emergir e fincar raízes na educação formal. Obviamente que tal tema deve ser trabalhado levando em conta a maturidade do educando. Com o presente trabalho pretende-se suscitar reflexões acerca do tema nos gestores políticos, equipe diretiva das escolas, professores do Ensino Básico e demais instituições que possam contribuir na construção de uma sociedade mais fraterna e solidária.

Espera-se que neste início de século inicie um novo desenho social, onde as distâncias serão encurtadas, os preconceitos enterrados e o amor praticado. Para tanto à escola está reservado um papel de destaque, contribuindo fundamentalmente para estabelecer laços coesos entre jovens e idosos: aquele que outrora embalou seu berço com braços rijos e mãos firmes, hoje, lhe estende seus braços frágeis, esperando encontrar o que nunca lhe negou: um abraço significativo. Também não se pode olvidar da importância da relação entre os próprios idosos, somando-se uns aos outros na busca de melhores dias nos mais variados aspectos.

Seria muita pretensão imaginar esgotar neste artigo todas as implicações que o tema acarreta, mas se deseja despertar, principalmente nos trabalhadores da educação um novo horizonte que traga ao cenário educacional mais conhecimentos a respeito da temática,

\footnotetext{
${ }^{3}$ O presente trabalho é baseado na dissertação de Mestrado em Educação na Pontifícia Universidade Católica do Rio Grande do Sul, realizado com bolsa da CAPES e com a orientação do prof. Dr. Juan José Mouriño Mosquera.
} 
validando a velhice como fonte de imersão no cotidiano brasileiro, visto que dados apontam, como veremos, um significativo aumento dessa população.

\title{
UM OLHAR SOBRE A VELHICE
}

A longevidade é uma árdua conquista do século XX que, com a queda da natalidade e o avanço da Medicina está ocasionando um vertiginoso envelhecimento da população mundial, tornando-se assim um fenômeno. O tema vem sendo abordado em países desenvolvidos e em países do terceiro mundo, citando Zimerman (2000, p. 14):

\begin{abstract}
$\mathrm{Na}$ fase pré-industrial, a maioria dos países do mundo vivia um momento em que tanto a natalidade quanto a mortalidade eram altas. A partir do advento da Revolução Industrial, no século XIX, começou a haver redução tanto da natalidade como da mortalidade e, na etapa pós-industrial, acelerou-se o controle de doenças infecciosas, com maior atenção à saúde em geral e, em particular, às doenças degenerativas e crônicas, típicas dos velhos.
\end{abstract}

Na ótica da autora, após a Segunda Guerra Mundial, foi visível o fenômeno denominado baby-boom, referindo-se ao elevado crescimento na taxa de natalidade, especialmente nos países da Europa e nos Estados Unidos. Entre os países da América Latina, o Brasil é o país que vem apresentando maior aumento na população de idosos.

Estima-se que até 2025 seremos o sexto país do mundo com o maior número de pessoas idosas, fenômeno visível também nos Estados Unidos e Europa. Como sinaliza a autora ocorrerá o "velho-boom", as pessoas que nasceram no pós-guerra estarão na faixa que vai dos 65 aos 80 anos, o que, ainda diz a autora, sem dúvida terá uma repercussão social. Que providências a sociedade como um todo está tomando frente a essa realidade já presente? No contexto brasileiro, em especial, é grande a desinformação sobre o idoso e as particularidades do envelhecimento humano.

Com o advento do Estatuto do Idoso, Lei n. 10.741, de 10 de outubro de 2003, trazendo em seu bojo uma gama de direitos aos destinatários em sua fase idosa, dá-se um pontapé inicial para a definição da Política Nacional do Idoso. Pontualmente, urge fazer cumprir este célebre código que veio inaugurar em nosso país novos rumos, permitindo reflexões e indagações. Vale lembrar que para a Organização Mundial da Saúde, idosas são as pessoas com mais de 65 anos. Segundo Zimerman (2000), tal referencial é válido para os países desenvolvidos, já para países em desenvolvimento como o Brasil, a terceira idade começa aos 60 anos. O próprio Estatuto do Idoso contempla a idade cronológica de 60 anos para referir-se ao idoso. 
Aponta-se, ademais que sabiamente quis o legislador brindar a educação brasileira com um mecanismo legal para que a mesma também disponha desta útil e preciosa ferramenta: O Estatuto do Idoso. Daí, as considerações finais presentes no instrumento acima citado, trazidas pelo Senador Paulo Paim (2008, p. 28), consta:

[...] Sabemos que o maior legado que podemos deixar para as gerações que estão se constituindo é a educação voltada para o respeito aos direitos humanos. Só é possível uma harmonia que escapa da violência, dos maus-tratos na infância e na velhice, dos salários indignos, das piores condições de sobrevivência, do sofrimento e do abandono social quando existir o respeito e a valorização do outro, da natureza e da humanidade. [grifo nosso]

Dessa forma, assim prevê a respectiva lei, in verbis:

Art. 25- Nos currículos mínimos dos diversos níveis de ensino formal devem ser inseridos conteúdos voltados ao processo de envelhecimento, ao respeito e à valorização do idoso, com o objetivo de eliminar preconceitos e disseminar esses conhecimentos.

Sendo os valores elementos constitutivos da educação, necessita-se construí-los, aclará-los, desvendar o que se almeja, portanto a prática educacional deve espelhar os valores que se quer implementar em nosso meio social.

Com o aumento da expectativa de vida e conseqüente modificação na pirâmide etária do país, cada vez mais se percebe a importância de conhecer o desenvolvimento do adulto, com ênfase ao idoso ou adulto tardio, como costuma referir-se o Dr. Mosquera. Desencadeia, assim, a necessidade dos profissionais da educação de conhecer assuntos que norteiam o desenvolvimento do adulto, pois junto a ele está a criança, a próxima geração escolar a conviver na comunidade.

Pois, hoje é comum presenciar avós que acompanham à escola os netos na idade primária e, em muitos lares, com suas aposentadorias representam o sustentáculo da família. Muitas vezes, entender esse vovô que se aproxima do meio escolar, esse vovô que aporta ganho financeiro, dentre outros, pode ser a fórmula para impulsionar uma convivência afetuosa e respeitosa no meio social. Como a educação pode contribuir com esse segmento populacional? Essa é a tônica principal desse artigo.

Evidente que é difícil assimilar o que não se conhece. Há um vazio cultural sobre as alterações morfobiológicas e psicossociais que acompanham o processo de envelhecimento. Através de alguns suportes teóricos aqui oferecidos, pode-se propiciar reflexões e apontar indicadores para uma possível implementação de conteúdos sobre aqueles "cabelos brancos" que trazem um histórico e dificuldades acarretadas pelos anos que já não lhes 
permite as facilidades dos jovens. A idade Ihes dá uma gama de sabedoria, mas Ihes rouba, Ihes deteriora estruturas físicas, psíquicas, dentre outras.

É necessário estimular uma educação intergeracional, rechaçar preconceitos tão arraigados que não agregam harmonia, paz, elementos tão necessários na sociedade vigente, como preceitua Néri (2006, p. 14):

Pode-se dizer que atitudes negativas, crenças incorretas, preconceitos e estereótipos em relação à velhice são tão velhos quanto à rejeição do ser humano à dependência, ao sofrimento, à doença e à morte, que se tornam cada vez mais prováveis com o envelhecimento.

Tais assertivas em relação à velhice podem ser mudadas, mas onde iniciar esse processo? Na família e nos bancos escolares. É aí que se pode trabalhar, discutir, refletir e quebrar as barreiras culturais e afetivas que norteiam a sociedade e faz com que direitos dos idosos sejam desrespeitados.

É educando que se resgatam valores, empreendem-se novos cidadãos e dissemina-se o bom, o belo e a sociedade de cultura de paz que todos almejam. Dar as costas aos idosos é dar as costas ao futuro de todos, pois sabidamente, por ordem natural este é o caminho, esta é a etapa pela qual se passará e não se pode negar seu espaço.

Aquilo que se planta é o que certamente se colherá. Boas sementes geram bons frutos, preparar o solo, fertilizar as escolas com cândidos olhares para com o idoso e conclamar a sociedade para participar, vestir a todos com os escudos do amor e da solidariedade é traçar um caminho salutar. Nobreza é dividir afeto, deixar nossos precedentes fartos de amor e compaixão, cercar-lhes de carinho e de respeito.

Os "velhos" e aqui colocado de forma carinhosa e respeitosa, são a memória, a história e um vínculo indissociável com a realidade, advindos que se é de um encontro também genético, porque não se nasce de uma geração espontânea, se é a soma dos que precederam e isso é fato é ciência e não se pode negar, sob o risco de ser sepultado o que se é. A herança dos antepassados é inegável.

Dessa forma, abre-se a possibilidades de criar na sociedade outro cenário, quebrando tabus e resistências, apontando possíveis caminhos, ratificando o convite para o desafio de implementar assunto tão relevante para que esteja presente nos currículos escolares, em especial, no Ensino Fundamental. 
Como tão bem colocou Beauvoir (1970) a velhice é uma "realidade trans-histórica". A sociedade numa época ou outra viu o velho com olhos diferentes. Nesta linha, Loureiro (1998, p. 25) afirma: “A aceitação ou a negação da velhice variam nas culturas e de uns para outros pensadores".

A velhice é produto de uma cultura, cada grupo tece o seu modelo de velhice. Segue na mesma direção, Dr. Juan Mosquera (1978, p. 201), quando fala na Psicologia do desenvolvimento humano, onde os estágios da personalidade revelam o desenvolvimento histórico e padrões comportamentais da sociedade da época. Segundo ele: "O intercâmbio história-homem é, sem dúvida, qualitativo e não apenas quantitativo. A história também amadurece e os sintomas da história nos revelam os sintomas das pessoas".

\section{APROXIMANDO GERAÇÕES ATRAVÉS DA EDUCAÇÃO}

Há jovens cansados e velhos de espírito e há idosos ousados e jovens de espírito. 0 mito de que fazer é exclusividade do jovem já não merece acolhida. A escola buscando trabalhar as relações humanas e interpessoais, levando em consideração as temáticas e vieses abordados anteriormente, gerará pessoas mais sadias, com condições de fazer e receber críticas. A vida é formada de ciclos. Ser idoso é fazer parte de um dos ciclos da vida onde também é permitido recomeçar.

O porquê de nossa existência é a pergunta que nunca quer calar. A presente indagação faz parte das fases da vida, porém na fase tardia, talvez ela seja mais latente e, cabe à sociedade responder que a capacidade humana vai além da capacidade física, alimentando a seiva do arranjo existencial que é a vida, pode-se experimentar o doce prazer de reinventar a própria existência a cada dia.

É no ambiente escolar com todos os atores e direção que se pode fazer a melhor performance: valorizar a dinâmica da vida. Ressaltando: a possibilidade do tema do idoso e sua valorização fazer parte dos currículos escolares pode significar um desafio, um pensar ousado para estabelecer uma ética solidária além dos muros escolares.

Nesse diapasão, vê-se que na sociedade atual onde é tão importante a imagem, onde o consumismo é desenfreado e que é incessante a busca da eterna juventude, ser velho parece ser degradante. Por um lado temos os fatores biológicos, inerentes ao ciclo da vida, mas a cultura de que o vigor, a chama da vida esteja somente no jovem é um equívoco. 0 envelhecimento é algo temido, até mesmo por falta de conhecimento. 
A própria literatura, muitas vezes, nos dizeres de Mucida (2006) utiliza o termo envelhecimento no sentido negativo. Associa-se muitas vezes a velhice com doença e decrepitude, como se nada mais restasse nessa etapa da vida. Nesta direção, Mosquera e Stobäus (2006, p. 129) salientam "que a conexão entre os sentimentos e o processo cognitivo propicia à pessoa uma vida de grande sensibilidade, que pode ser cada vez mais apreciada, na medida em que cada um desenvolve a sua capacidade afetiva e suas potencialidades diferenciais".

Disso resulta a importância das práticas escolares saírem do papel, buscando estimular ideal humanista. A educação não pode ser mais espaço somente para discursos políticos e maniqueístas. Os princípios mais solidários e fraternos fazem parte do ideário pedagógico e a própria lei traz no seu bojo valores desta natureza, mas se não forem praticados não frutificarão.

Despertar a afetividade, entender as emoções, não somente privilegiar o cognitivo pode ser o começo para uma nova ordem social. Lembrando a sábia colocação: "as emoções nunca têm sido muito populares em nossa civilização, especialmente nos últimos séculos, por isto o controle e a ausência de emoções foi considerada uma conquista preciosa do ser humano, em certos segmentos sociais" (MOSQUERA; STOBÄUS, 2008, p. 110).

As emoções e a afetividade são indispensáveis para o entendimento da pessoa como um ser completo. Somos um intercâmbio de relações, um somatório do corpo e alma. Por certo, a autonomia é importante, mas um fazer pedagógico equilibrado pode estabelecer novos rumos para o ser humano.

Citando Mahoney (2000, p. 85):

[...] toda prática verdadeiramente pedagógica tem por finalidade o desenvolvimento da pessoa e o fortalecimento do eu. Sua intenção, portanto, tem de ser levar o aluno a fortalecer a auto-estima, ter confiança em si e nos outros, ter respeito próprio. E, assim fortalecido, pode ser solidário em suas relações.

O currículo escolar deve abarcar conteúdos que visem à inteireza do ser. Repisando: o trabalho da educação deve ser voltado para formar o cidadão integralmente, como afirma Morin (2005, p. 11): “Uma educação só pode ser viável se for uma educação integral do ser humano. Uma educação que se dirige à totalidade aberta do ser humano e não apenas a um de seus componentes". Isso quer dizer que uma educação do futuro deverá abranger o ser humano em todas as suas fases orgânicas de vida: da infância à terceira idade, sendo o indivíduo educado desde pequeno à compreensão de que um dia também será idoso. 
Sabe-se que o sentido de velhice decorre da visão que a sociedade imprime. Habilmente impõe-se: a escola pode fazer uma nova sociedade. Cada cultura traz a maneira de tratar seus antecessores. Numa época ou em outra, as sociedades encararam a velhice de forma variada, acompanhada de aspectos paradoxais.

De uma ótica pessimista chega-se a uma mais realista, porém neste terceiro milênio, sem dúvida, com essa população emergente, o tema requer mais conhecimentos técnicos e científicos para se saber que processo é esse que cerca a todos nós e espreita a vida a cada aniversário que se comemora? O que se sabe sobre o envelhecimento, o que se conhece sobre esse processo, desde sua historicidade até os dias atuais?

Ora a escola terá que preencher essa lacuna. Morin (2005) em seu livro Os sete saberes necessários à educação do futuro trata da necessidade de promover o conhecimento capaz de apreender problemas globais e fundamentais para neles inserir os conhecimentos parciais e locais. Não há mais dúvida e os dados apontam para um crescimento demográfico mundial da população de idosos, eis um problema global, mas muito perto de nós, brasileiros, cujos dados registram, repetindo: em 2025 seremos o 6o país do mundo em número de idosos e, no Rio Grande do Sul, tem-se a cidade de Veranópolis, a terra da longevidade, portanto, é crucial permear as atividades escolares, com a realidade da velhice tão próxima.

O autor também faz uma crítica ao conhecimento cada vez mais compartimentado, 'fragmentado' que impede de operar o vínculo entre as partes e o todo; devendo, conforme Morin (2005, p. 14):

[...] ser substituída por um conhecimento que envolva o contexto, a complexidade e o conjunto daquilo que foi aprendido. O 'espírito humano' possui uma capacidade natural em situar todas as informações apreendidas em um contexto e um conjunto; isso deve ser aproveitado e desenvolvido [...].

É preciso estimular o aluno a estabelecer as relações mútuas e as influências recíprocas entre as partes e o todo em um mundo complexo. Assim, pode ser inserido também o tema do idoso em sala de aula, mostrando aos alunos que, como criança ou jovens, eles têm o seu próprio universo, mas também faz parte de um universo maior. Neste universo maior existem outros indivíduos, pertencentes a outras fases da vida, as quais eles irão mais tarde participar. E ao participarem dessa outra fase (velhice), gostarão de ser respeitados assim como querem e devem ser respeitados como crianças que são. 
Na perspectiva de Morin (2005) é discutida outra realidade ignorada pela educação: o destino planetário do gênero humano. Para o autor, o reconhecimento da identidade terrena se tornará cada vez mais indispensável a cada um e a todos devendo se converter em um dos principais objetos da educação. Além disso, deve-se também ensinar a história da era planetária e mostrar como todas as partes do mundo se tornaram solidárias, como o Morin (2005, p. 55) aponta: “[...] será preciso indicar o complexo de crise planetária que marca o século $\mathrm{XX}$, mostrando que todos os seres humanos, confrontados de agora em diante aos mesmos problemas de vida e de morte, partilham um destino comum".

Os seres humanos possuem os mesmos direitos. Essa é a obrigação que a educação deve desde já programar: "ensinar a igualdade entre os seres humanos". A escola deve ensinar a "estar aqui" no planeta e aprender a estar aqui significa: aprender a viver, a dividir, a comunicar, a comungar. A criança que aprende essas noções na escola respeitará o outro (seja ele quem for: jovem, adulto, idoso) e será um adulto respeitador dos direitos e condições humanas do seu próximo, pois a "sociedade como um todo está presente em cada indivíduo". Mais uma vez, a importância de se colocar no currículo escolar conteúdos que ensinem todos a respeitar, a conviver e principalmente a compreender o idoso e essa fase da vida pela qual todos passarão. Com essa educação voltada à inclusão do idoso numa sociedade que o aceita, respeita e o compreende, ele se sentirá mais útil e mais feliz e mais consciente do seu próprio papel na sociedade, espelhando Morin (2005, p. 55): "todo desenvolvimento verdadeiramente humano significa o desenvolvimento conjunto das autonomias individuais, das participações comunitárias e do sentimento de pertencer à espécie humana".

Cabe também apor os dizeres de Durand (1989, p. 296): “um humanismo planetário não se pode fundar sobre a exclusiva conquista da ciência", há que se sedimentar sobre as bases da solidariedade. Também se pode falar em ética planetária (tema abordado no Fórum Mundial de Educação em Santa Maria/RS em maio de 2008), ética essa baseada na defesa da vida e das relações solidárias entre as pessoas. O homem é o que faz a si e como já foi dito: em constante processo de atualização sócio-cultural. Costurando com as colocações de Morin (2005), extrai-se que a ética planetária abarca o destino planetário do homem.

A escola pode ser o espaço para tecer as particularidades culturais locais, inserindoas no global, permitindo a construção da universalidade. Não se está isolado, os problemas 
repetem-se, há questões comuns às diferentes comunidades. A ética planetária é fundamentada na justiça social, sendo transcultural, transracial e supra-econômica.

\section{REFLETINDO SOBRE O tempo em cada tempo da vida}

Sempre se ouve: tudo tem seu tempo. A própria natureza, quer nas suas estações, quer nas fases da lua, quer no movimento das marés está impregnada de ciclos. O homem também faz parte da natureza e passa por ciclos. Negar tal condição é negar que não se nasce, não se cresce e que não se morre. Cada fase vem permeada de suas peculiaridades.

O tempo é uma passagem, talvez somente percebida quando se depara com o espelho, onde a imagem é refletida. Enrugar pode ser um processo doloroso, dependerá da visão de mundo que se tem, mas cada ruga é tão particular e única e vem eivada de acontecimentos alegres, tristes, enfim de experiências únicas, ímpares.

Nos dizeres de Néri (1991, p. 17-8): “O tempo é um ente natural que determina o destino dos homens, ao permitir a vida a cada dia, mas a leva consigo a medida do seu transcurso. Ele desgasta, amadurece ou devasta as pessoas. Apura suas qualidades, como o faz com os vinhos".

Experimentam-se a cada dia, horas a menos, meses, anos... Não se pode esquecer que são artefatos como o relógio e o calendário que arbitram o tempo, mas e a experiência de vida, como mensurá-la? Nenhum objeto está á disposição para tanto. As atitudes, o comportamento, a forma como se responde diante de problemas que se apresentam no diaa-dia dão pistas de como foi elaborada a vida em fases anteriores e as respostas que se dá ao mundo dão conta dos passos e caminhos escolhidos de como se vive a fase tardia.

Assim, seguem-se as diferentes possibilidades de entendimento quanto ao tempo. Ressalte-se que aqui, não se aprofunda a questão, mas se tece condições para os que desejam acrescentar diferentes estudos ao tema.

É pertinente trazer à tona a colaboração de Loureiro (1998, p. 57-65), baseada na obra As culturas e o tempo de Paul Ricoeur (1975), noções através de algumas culturas de como é visto o tempo. O autor traz Claude Larre sobre o tempo para os chineses: "tem todo um vocabulário de tempo e certa lógica na concepção e na organização do tempo, nas palavras e em toda vida". Ainda traz a noção de tempo para os hindus em Raimundo Panikkar, que repousa, sobretudo, em um "cuidado espiritual da superação do tempo". No seu livro sagrado: Vedas encontram-se expressões como tempo vital, duração da vida, 
tempo de sacrifico. Para esse povo, nos dizeres de Panikkar, o tempo é "um destino inelutável, que conduz à velhice e por fim à morte".

Também na cultura bantu, trazida por Alex Kagame o que importa é o "tempo disso ou daquilo, o tempo propício para isso e aquilo". Esse povo tem uma cultura sem escrita, então colocações são empíricas. "O tempo é uma entidade incolor, indiferente, enquanto um fato concreto não sobrevém para marcá-lo, selá-lo". Ainda em Ricouer, lembrando Lloyd: os gregos não tinham uma concepção única de tempo.

O mesmo autor refere-se às diferenças entre deuses e homens. Os primeiros são imortais; e os homens são expostos à velhice, assim há uma aceitação da irreversibilidade da velhice e sua aproximação com a morte.

O tempo cristão para Ricouer caracteriza-se "pelo ritmo de nossas semanas e anos, no qual o conjunto da comunidade cristã deixou sua marca temporal". Como sublinha Altair Loureiro (1998) as concepções cristãs de tempo são variadas, pois várias são as formas confessionais de cristianismo. Ainda, aponta-se, vagamente, o tempo para os muçulmanos, que faz alusão há um tempo divino, conforme Gardet.

Ressalte-se que aqui, não se aprofunda a questão do tempo e suas possibilidades de entendimentos, apenas abre-se caminhos para melhor situar essa temática, ao apontar a diversidade de relações com a natureza. O tempo é o tempo que se vive. Sendo uma dimensão abstrata o sentimos quando o experimentamos a cada dia. Rotular o tempo nomeá-lo é preocupar-se com o invólucro e não com o conteúdo. O tempo, enquanto cronológico para o adulto tardio, serve muitas vezes para estereotipias vulgares e impiedosas.

As "idades do homem" são puras invenções sociais: o conceito de infância emergiu nos séculos XVIII e XIX, o de adolescência em fins do século XIX e o de juventude 20 ou 25 anos atrás. O conceito de meia-idade como etapa intermediária entre a idade adulta e a velhice data dos anos 60 . Os anos 70 assistiram a promulgação do conceito de 'velhice avançada', sem dúvida um fato social e demográfico novo na história da humanidade" (ÁRIES e colaboradores apud NÉRI, 1991, p. 17-8).

A cultura vivenciada hoje é on-line, o tempo é dinheiro no mundo ocidental, principalmente na sociedade em que se vive. A rapidez com que tudo acontece, a inquietação que as mudanças provocam, aponta para a angústia do inesperado. Clama-se por soluções ecologicamente corretas, mas o homem não sabe viver sem poluir, grita por 
paz, porém arma-se para mantê-la, pede socorro a Deus, mas não cuida, muitas vezes, do lado espiritual. Não se quer violência, mas se fecha o nariz e se tapa os olhos, quando passa um mendigo mal-cheiroso. Necessita-se de leis para um afro-descendente ser respeitado pela cor que sua pele possui, lei para que o idoso seja respeitado, onde está o mais humano nos seres humanos?

Tem-se medo de arriscar, de romper paradigmas, mas o mundo atual exige uma nova forma de comportamento, uma nova educação. Hoje, em meio a tanta tecnologia e globalização, torna-se necessário e vital explorar, trabalhar as emoções. Os jovens, tão ávidos de luzes, sons e cores e tão imersos em incertezas necessitam encontrar na escola uma orientação para seus sentimentos.

Não há mais espaço para rechaçar a afetividade e a emoção, elementos que devem, no mínimo, serem considerados nos currículos escolares. A sociedade que se quer, depende muito da escola que se tem, da educação que se oferta. A mudança deve ser motivada, deve ser significativa para toda a sociedade, a começar pela comunidade escolar, envolvendo a todos na busca de uma solidariedade planetária.

Quando não se cuida da alma e da sagrada morada que é o corpo e não se alicerça com solidariedade e com ética o cotidiano e não se costura com fios de esperança e afeto a sociedade, criva-se a existência de mal-estar. Então, o tempo é meu tempo de cada dia, pode-se fazê-lo aliado. A minha subjetividade permeia minha existência, esse é o meu tempo.

Nesta direção aponta Heidegger (1962), em O ser e o tempo, quando diz que o homem é um ser temporal e a temporalidade dá sentido à existência. O que reserva o futuro? Buscam-se muitas respostas, mas elaborá-las também é um caminho a ser percorrido. Não se pode olvidar que os sinais visíveis que a velhice traz não são meramente orquestrados por números.

Aferir a idade somente sob essa égide traz preconceito e discriminação. Afinal, que seria de cada um sem os avós, pais? Quantas vezes se recorrem a eles para uma opinião, um acolhimento? A velhice depende, sobretudo, de ponto de vista de cada um. Restringir as etapas da vida a simples condicionantes: infância é tempo de brincar, a fase adulta de trabalhar, casar, ter filhos e a velhice de sossegar é limitar as possibilidades de desenvolvimento da pessoa humana em qualquer etapa de sua vida. 
Será que alguém ousaria chamar de decrépito ou senil a John Glenn? Nascido em 1921 e que aos 77 anos em 29/10/1998, torna-se a pessoa mais velha a tocar o espaço sideral. Glenn foi submetido a testes físicos extremamente exigentes logrou êxito submeteuse a mais de 500 horas de treinamento. Glenn já havia estado no espaço sideral em 1962, aos 40 anos. Sem dúvida, sua audácia quebrou estereótipos sobre o envelhecimento. É um ser humano com grandes potencialidades, como o poderia ser um jovem. (PAPALIA; OLDS; FELDMAN, 2006).

A complexidade do ser humano é curiosa: é criança se comparada a um adolescente ou adulto, jovem se comparado ao idoso. Demonstra assim que depende de qual ângulo observa-se para delimitar um ou outro. Assim, parece justo e fiel classificar não pela idade cronológica, mas por idade funcional (PAPALIA; OLDS; FELDMAN, 2006), ou seja, o quão bem uma pessoa funciona em um ambiente físico e social em comparação com outras da mesma idade cronológica. Uma pessoa de 90 anos que ainda está com boa saúde pode ser funcionalmente mais jovem do que uma de 65 anos que não está com sua saúde satisfatória. Não se pode prescindir de explanar a temática nos meios escolares, objetivando o entendimento do idoso e a complexidade que o cerca.

Coelho $(1989$, p. 35) enfatiza a relevância do preparo do jovem na problemática que envolve o idoso:

Portanto, devo frisar que, a integração do idoso na família, não deve prescindir de um preparo do jovem, de uma conscientização dos problemas do idoso, suas dificuldades de relacionamento, de adaptação, para que o jovem possa aceitá-lo, bem como sua família, facilitando assim a integração.

A sociedade não pode abrir mão da experiência do idoso. O corpo, a estrutura orgânica do mesmo pode determinar-Ihe algumas dificuldades, mas o desejo de fazer pode continuar e a sede de novas descobertas também, vejam: "Acontece uma coisa interessante com o ser humano: a ideologia, o espírito progride mais rapidamente do que a estrutura. Descobrimos coisas novas, muito mais rapidamente do que a estrutura [...]" (COELHO, 1989, p. 34).

A velhice pode ser uma fase muito especial como qualquer outra, pode ser o momento em que a própria vida pode ser revisada e ampliada através das experiências acumuladas, permitindo buscar novas possibilidades. 
Lopes (2007, p. 142) em seu texto "Imagem e auto-imagem: da homogenidade da velhice para a heterogeneidade das vivências", afirma que:

Construímo-nos e reafirmamo-nos como sujeitos ao longo da vida, em uma sociedade, em uma cultura. Isso inclui relações de aliança e de conflito, solidariedade e dominação, inclusão e exclusão, e também pertinência e marginalidade. Vale a pena examinar como a cultura se torna co-responsável por boa parte dos sofrimentos dos mais idosos [...].

Conforme já comentado anteriormente em outra passagem sobre o reflexo da cultura na sociedade, é com a educação que se pode ajudar a construir novos pensamentos, novas atitudes e daí a possibilidade de alianças positivas acontecerem anunciando tempos de afeto e respeito para todos.

\section{REFERÊNCIAS}

BEAUVIOR, Simone de. A velhice: uma realidade incômoda. Trad. Heloísa de Lima Santos. v. I, São Paulo: Difusão Européia do Livro, 1970.

2008.

. Estatuto do Idoso. Lei n. 10.741, de 10 de outubro de 2003. Brasília: Fetapergs,

COELHO, Maria da G. O idoso isolado e as gerações. Florianópolis, IOESC, 1989.

COTRIM, Gilberto. História e consciência do mundo. 4. ed. São Paulo: Saraiva, 1996.

DELORS, Jacques. Educação: um tesouro a descobrir. 3. ed. São Paulo: Cortez, 1999.

DURAND, Gilbert. As estruturas antropológicas do imaginário. Introdução à arquetipologia geral. Lisboa: Presença, 1989.

LOPES, Ruth Gelehrter da Costa. Imagem e auto-imagem: da homogeneidade da velhice para a heterogeneidade das vivências. In: NÉRI, Anita L. (orgs.). Idosos no Brasil: vivências, desafios e expectativas na terceira idade. São Paulo: Editora Fundação Perseu Abramo, Edições SESCSP, 2007, p. 142-7.

LOUREIRO, Altair Macedo Lahud. A velhice, o tempo e a morte. Brasília/DF: Editora UnB, 1998.

MAHONEY, Abigail; ALMEIDA, Laurinda (org). Henry Wallon - Psicologia e Educação. São Paulo: Loyola, 2000.

MONSERRAT, Moreno et al. Falemos de sentimentos: a afetividade como um tema transversal. São Paulo: Moderna, 1999. 
MORIN, Edgar. Os sete saberes necessários à educação do futuro. São Paulo: Cortez, 2001. . O enigma do homem. São Paulo: Círculo do Livro, [s.d.].

MOSQUERA, Juan J. M. Vida adulta: personalidade e desenvolvimento. Porto Alegre: Sulina, 1978.

. A Educação no Terceiro Milênio. Educação, Porto Alegre, Ano XXVI, Especial, p. 4358, set. 2003.

; STOBÄUS, Claus D. Afetividade: a manifestação de sentimentos na educação. Educação, Porto Alegre, PUCRS, ano XXIX, n. 1, p. 123-34, jan./abr. 2006.

. Auto-Imagem, Auto-Estima e Auto-Realização na Universidade. In: ENRICONE, Délcia (org.). A docência na educação superior: sete olhares. 2. ed. Porto Alegre: Edipucrs, 2008a

MUCIDA, Ângela. O sujeito não envelhece: psicanálise e velhice. 2. ed. Belo Horizonte: Autêntica, 2006.

NÉRI, Anita L. Envelhecer num país de jovens: significados de velho e velhice segundo brasileiros não idosos. Campinas: Editora da Universidade Estadual de Campinas - UNICAMP, 1991.

. Atitudes e crenças sobre velhice: análise de conteúdos de textos do jornal O Estado de São Paulo publicados entre 1995 e 2002. In: VON SIMSON, Olga R. de M.;

CACHIONE, Meire (orgs.). As múltiplas faces da velhice no Brasil. 2. ed. Campinas: Alínea, 2006, p. 14-54.

PAPALIA, Diane E.; OLDS, Sally Wendkos; FELDMAN, Ruth D. Desenvolvimento humano. 8. ed. Porto Alegre: Artmed, 2008.

ZIMERMAN, Guite I. Velhice aspectos biopsicossociais. Porto Alegre: Artmed, 2000, reimpressão, 2007. 